\title{
LA LIBERTAD DE EXPRESIÓN EN LAS SENTENCIAS DE LA SUPREMA CORTE DE JUSTICIA
}

\section{Carlos Martín GÓMEZ MARINERO*}

Si bien la libertad de expresión constituye un derecho individual, lo cierto es que también significa una protección de la soberanía popular. Esta circunstancia permite explicar por qué los intereses de quienes se expresan deben tener prioridad sobre los intereses de los individuos acerca de los cuales se discute, cuando aquéllos entran en conflicto con éstos (como lo señala Owen Fiss en su obra La ironía de la libertad de expresión). Lo anterior se corrobora con el reconocimiento de las dimensiones individual y social de la libertad de expresión, que deben ser garantizadas simultáneamente por el Estado. ${ }^{1}$

La obra que se reseña parte de la premisa antes destacada, en la medida que se enfoca en analizar las sentencias de la Suprema Corte de Justicia — entre marzo de 2000 y marzo de 2013 - relacionadas con la libertad de expresión. Las quince resoluciones estudiadas en la obra se derivan de un amparo en revisión conocido por el Pleno, así como dos amparos en revisión, seis amparos directos en revisión y seis amparos directos decididos por la Primera Sala. En la mayoría de estos asuntos se advierte la construcción y el desarrollo de la "doctrina constitucional" de la Corte mexicana en materia de libertad de expresión. ${ }^{2}$

La parte introductoria del trabajo destaca la posibilidad de intervención del juzgador en relación con los diversos sujetos que participan en los conflictos de la libertad de expresión: $a$ ) persona privada; $b$ ) periodista;

\footnotetext{
Maestro en derecho constitucional y administrativo por la Universidad Veracruzana; secretario de Estudio y Cuenta en el Instituto Veracruzano de Acceso a la Información y Protección de Datos Personales,gomez_mcm@hotmail.com.

1 Por ejemplo, el caso Claude Reyes y otros vs. Chile, 2006, párr. 77, y la Tesis la. CDXIX/2014 (10a.), Gaceta del Semanario Judicial de la Federación, Décima Época, libro 13, t. I, diciembre de 2014, p. 234.

2 Reconocida en el amparo directo 8/2012 y el amparo directo en revisión 2806/2012, ambos de la Primera Sala de la Suprema Corte de Justicia.
} 
c) persona pública; d) medio de comunicación, y e) autoridad. Esta distinción permite, a su vez, advertir las condiciones simétricas o asimétricas en las controversias de esta naturaleza, lo que se puede palpar con un grado de generalidad en las sentencias analizadas.

Los autores de la obra precisan que la Suprema Corte no ha conocido ni resuelto todos los supuestos posibles conflictos; no obstante, analiza cinco clases de conflictos: a) persona privada contra autoridad; $b$ ) persona privada contra medio de comunicación; c) periodista contra persona pública; d) persona pública contra persona pública, y e) medio de comunicación contra medio de comunicación.

En el caso de las controversias entre personas privadas contra autoridades, se analizan tres amparos en revisión: 2352/1997, ${ }^{3}$ 2676/20034 y 1595/2006, de los cuales destaca el último de los mencionados, en el que se estudió la constitucionalidad de una norma municipal que exigía solicitar permiso previo a las autoridades para difundir o repartir documentos en la vía pública y si esa norma vulneraba las libertades de expresión, imprenta o religiosa. Lo importante del precedente — destaca el texto- es que la Corte estableció una metodología para determinar la inconstitucionalidad de una norma: 1) identificar los hechos relevantes y desarrollar su función y ámbito de protección en el ordenamiento jurídico; 2) armonizar el ejercicio del derecho en cuestión con otros que estuvieran relacionados, y 3) evaluar la norma que se considere inconstitucional. Asimismo, la Corte reconoció la dimensión individual y pública o social de la libertad de expresión, cuestión que es muy importante, pues como se ha señalado, ésta no sólo se concibe como un elemento de autorrealización personal, sino también para la construcción democrática.

Tocante a los conflictos entre personas privadas contra medios de comunicación, se analizan cuatro asuntos resueltos por la Primera Sala: dos amparos directos en revisión (1496/20085 y 1302/2009) y dos amparos di-

3 Resuelto por el Pleno de la Corte el 6 de marzo de 2000. Asunto de menor importancia — desde el punto de vista de la construcción de la doctrina de libertad de expresión-. En él se analizó el reclamo de la United International Pictures, S. de R. L., debido a la negación de la distribución y exhibición de la película Jurassic Park doblada al español.

4 Resuelto el 5 de octubre de 2005. En el caso Bandera (también conocido como "Poema maldito"), los ministros de la mayoría validaron la constitucionalidad del delito de "ultraje a las insignias nacionales". Lo destacado en este asunto lo constituye el voto de la minoría (Silva Meza y Cossío Díaz), en el que se destacó la vertiente pública de la libertad de expresión y la importancia de proteger las libertades de expresión e imprenta tratándose de materia política.

5 Resuelto el 5 de noviembre de 2008. En él no se desarrollan precedentes para el impulso de la doctrina constitucional en materia de libertad de expresión. En el asunto se 
rectos $\left(8 / 2012^{6}\right.$ y 16/2012). ${ }^{7}$ Resulta de significativa importancia el amparo en revisión 1302/2009, cuyo objeto de estudio lo constituyó el análisis de la censura previa y el derecho a la libertad de expresión, reseñando las razones por las que no debía imponerse a los periódicos la obligación de revisar el contenido de cada una de las inserciones que les solicitan. Sin embargo, la Corte reconoció la necesidad de establecer mecanismos para que los terceros respondan por las extralimitaciones o ilicitudes en que pudieran incurrir con motivo de la manifestación de ideas. En este asunto se refleja un avance importante en torno a los alcances de la libertad de expresión en los medios de comunicación.

Con relación a los conflictos entre periodistas y personas públicas, se examinaron el amparo en revisión 2044/2008 y los amparos directos 6/2009 y $12 / 2009,{ }^{8} 25 / 2010^{9}$ y $3 / 2011.1^{10}$ Dentro de este grupo es significativo el primero de los asuntos enunciados, conocido como caso Acámbaro, uno de los primeros que contribuyó a la construcción de la doctrina de la Suprema Corte de Justicia en la materia y cuya referencia constante en otras sentencias del mismo tribunal evidencian su trascendencia. En el texto se destacan los antecedentes: el director de un periódico realizó una entrevista al ex chofer del entonces presidente municipal de Acámbaro, Guanajuato, en la que señaló que el funcionario había empleado recursos públicos para fines personales y reveló detalles en torno a su conducta sexual.

$\mathrm{Al}$ conocer de este caso, la Primera Sala, considerando la jurisprudencia de la propia Corte Interamericana — principalmente el caso Herrera Ulloa vs. Costa Rica-, identificó el tipo de conflicto, reconociendo la vertiente privada y social de las libertades de expresión e información, y razonando de acuerdo a sus propios precedentes, que cuando un tribu-

determinó que no se violó la libertad de expresión, porque, a su vez, no se vulneró la Ley sobre Delitos de Imprenta del Estado de Tabasco.

6 Sesionado el 4 de julio de 2012. La importancia de este asunto radicó en las explicaciones en torno a la proyección pública de las personas.

7 Resuelto el 11 de julio de 2012. En este caso se analizó un conflicto de derechos entre las libertades de imprenta y expresión y el derecho al honor y la vida privada, destacando los alcances y rasgos característicos de "lo privado" y las dimensiones del derecho al honor (objetiva y subjetiva).

8 El 6/2009 fue promovido por Marta Sahagún, y el 12/2009, por su parte, por la periodista Olga Wornat (resueltos ambos el 7 de octubre de 2009). En cuanto a la relación entre el derecho a la privacidad, la libertad de expresión y el derecho a la información, se retomaron los argumentos del caso Acámbaro.

9 Resuelto el 3 de noviembre de 2011 . Principalmente, en este asunto se retomaron los argumentos del caso conocido como La Jornada vs. Letras Libres (amparo directo 28/2010).

10 Fallado el 23 de febrero de 2011 . Se advierte la influencia de lo resuelto en el amparo directo 28/2010 y se aborda el derecho de réplica. 
nal decide un caso de libertad de expresión, imprenta o información, está afectando no sólo las pretensiones de las partes en un litigio concreto, sino también el grado en que en un país quedará asegurada la libre circulación de noticias, ideas y opiniones.

En el libro se advierte que el caso Acámbaro, asimismo, dio lugar a la adopción del criterio proveniente de las resoluciones de organismos internacionales al analizar los conflictos de libertad de expresión, en el sentido que las personas que desempeñan o han desempeñado responsabilidades públicas, así como los candidatos a desempeñarlas, tienen un derecho a la intimidad y al honor, con menor resistencia normativa general que el que - asiste a los ciudadanos ordinarios frente a la actuación de los medios de - comunicación.

Esta parte —una de las de mayor relevancia en el texto - destaca que si las personas han decidido libremente dedicarse a una actividad de esta naturaleza, ello implica que se han sometido al escrutinio y difusión de información que forma parte de su vida privada y que deben mostrar mayor grado de tolerancia respecto de las críticas de los medios de comunicación. Asimismo, se advierten los lineamientos establecidos por la Corte para el análisis y asignación de responsabilidades derivadas de la emisión de opiniones en contra de servidores públicos.

$\mathrm{Al}$ analizarse las controversias entre personas públicas, en la obra se relata el amparo directo en revisión 284/2011, derivado del conflicto entre Manuel Bartlett y Germán Martínez; en el asunto se refieren los criterios relativos a la inviolabilidad parlamentaria (tema que habían argumentado los órganos que conocieron en instancias previas). Además, la Sala destacó la distinción entre la libertad de expresión (difusión de ideas) y el derecho a la información (difusión de hechos), pues a criterio de la Corte, en el primer caso lo relevante es determinar la veracidad y diligencia de la investigación realizada, mientras que en el segundo lo importante es analizar el contexto a fin de determinar si las expresiones son injuriosas o excesivas. Finalmente, en el libro se explican las razones para determinar cuándo se trata de un discurso de "naturaleza política".

En la parte final del trabajo se abordan los conflictos entre medios de comunicación. Para este efecto se reseñan tres asuntos: el amparo directo 28/2010 y los amparos directos en revisión $2411 / 2012^{11}$ y 2806/2012.12

11 Fallado el 5 de diciembre de 2012. En el asunto se analiza la dimensión del derecho al honor y su relación con la libertad de expresión de un periodista.

12 Sesionado el 6 de marzo de 2013. En el caso se determinó que el derecho al honor prevalece cuando la libertad de expresión utiliza frases y expresiones ultrajantes, ofensivas u oprobiosas - por conllevar un menosprecio personal o una vejación injustificada-. 
El primero de los asuntos citados es uno de los más importantes de los últimos veinte años, no sólo en materia de libertad de expresión, sino en general de los emitidos por la Suprema Corte de Justicia. En este caso, conocido como La Jornada vs. Letras Libres, se narran los antecedentes del asunto: la publicación de un artículo en la revista mensual, en la que se relacionaba a La Jornada con la organización terrorista vasca ETA, por lo que el periódico argumentó que la publicación constituía un ataque a su vida privada y honor - límites a las libertades de expresión e imprenta-. Después de un intrincado procedimiento (en el que la Corte ordenó dejar insubsistente la cuarta sentencia emitida por la Sala del Tribunal Superior de Justicia) se expone la manera en que la Corte desarrolló el alcance de sus propios precedentes en materia de libertad de expresión en relación con el derecho al honor; se razona que si bien existe una presunción general de cobertura constitucional de todo discurso expresivo, no todo discurso crítico está protegido, pues la Constitución no reconoce un derecho al insulto o a la injuria gratuita (argumento que sería retomado en el amparo directo en revisión 2806/2012).

En el texto se relatan los nuevos alcances del entendimiento de la figura pública — tradicionalmente atribuible a servidores públicos y particulares con proyección pública por su actividad política, profesión, trascendencia económica y por su relación social—, incorporando a los medios de comunicación, específicamente, a los líderes de opinión.

Si bien en la obra se refiere, principalmente, a los criterios de la Primera Sala de la Suprema Corte, lo cierto es que también son palpables - y así se reconoce a lo largo del texto- los razonamientos de la Relatoría Especial para la Libertad de Expresión de la Comisión Interamericana de Derechos Humanos, ${ }^{13}$ de la Corte Interamericana de Derechos Humanos, ${ }^{14}$ del Tribunal Europeo de Derechos Humanos ${ }^{15}$ y de la Suprema Corte de Justicia norteamericana, ${ }^{16}$ con información complementaria de doctrina y jurisprudencia en las notas al pie de página.

En síntesis, a través de una breve referencia de los antecedentes y del procedimiento del que derivan las controversias se analizan los argumentos

\footnotetext{
13 Los informes de la Relatoría Especial para la Libertad de Expresión de la Comisión Interamericana de Derechos Humanos (1999, 2000, 2001 y 2004).

14 Por ejemplo, Claude Reyes y otros vs. Chile; Fontevecchia y D'Amico vs. Argentina; Kimel vs. Argentina; Herrera Ulloa vs. Costa Rica, y la Opinión Consultiva OC-5/85 "Colegiación obligatoria de periodistas".

15 Por ejemplo, los casos Lingens vs. Austria (1986) y Hanover vs. Alemania (2004).

16 La tesis de real malicia, en el The New York Times Company vs. Sullivan (9 de marzo de 1964).
} 
Esta revista forma parte del acervo de la Biblioteca Jurídica Virtual del Instituto de Investigaciones Jurídicas de la UNAM

en cada caso concreto y se refieren los alcances de acuerdo al tipo de conflicto de la libertad de expresión, destacando la importancia de los asuntos más trascendentes que ha conocido la Suprema Corte (en nuestra consideración, los dos de mayor relevancia son el caso Acámbaro y La Jornada vs. Letras Libres). Los autores ponen el énfasis en los conceptos del sistema dual de protección, en la naturaleza de los sujetos involucrados, en el interés general, el test de la malicia efectiva o real malicia, la dimensión individual y social del derecho a la información y de la libertad de expresión, el grado de tolerancia y el escrutinio público, entre otros aspectos.

El trabajo representa una herramienta útil y práctica para comprender - los criterios, parámetros, límites y alcances del derecho a la libre expre- sión, que al participar — como todos los derechos humanos- del principio constitucional de interdependencia permite conocer su relación con el derecho a la información, a la intimidad, a la vida privada, a la libertad religiosa, a la libertad de imprenta, etcétera; por ello, no sólo es un texto que puede servir a quien se introduce al estudio del derecho constitucional, sino a los interesados en el derecho a la información, civil, penal, y, principalmente, a quien pretenda aproximarse al entendimiento y a la manera de argumentar de la Suprema Corte de Justicia de la Nación.

A su vez, el trabajo no descarta que en sucesivas ediciones se vayan incorporando las decisiones futuras de la Corte; por ejemplo, a la fecha, el Pleno ha resuelto el amparo directo en revisión 2255/2015 (el 7 de marzo de 2016), en el que se analizó la constitucionalidad de una norma que prevé el delito de ultrajes a la autoridad. Desafortunadamente sólo los ministros Cossío Díaz y Ortíz Mena estimaron la inconstitucionalidad de esta norma por violación a la libertad de expresión, pues el resto de ministros valoraron la vulneración al principio de taxatividad, lo que se aparta del enfoque y entendimiento desarrollado por la Primera Sala en esta clase de conflictos.

\section{Bibliografía deL Libro RESEÑAdo}

Cossío Díaz, José Ramón et al., 2014, La libertad de expresión en las sentencias de la Suprema Corte de Justicia, México, Tirant Lo Blanch. 